\title{
Prevalence of Gene Polymorphisms in Intervertebral Disc Degenerative Diseases
}

\author{
Mr. C. Marimuthu' ${ }^{1}$, Dr. V. Pushpa Rani², Dr. V. Judia Harriet Sumathy ${ }^{2}$ \\ ${ }^{1}$ Research Scholar, ${ }^{2}$ Assistant Professor \\ Department of Advanced Zoology and Biotechnology, Loyola College, Chennai, India
}

\begin{abstract}
Intervertebral disc diseases is otherwise known as breakdown of one or more discs that separate the bone of the spine, Which cause pain in the back, neck as well as frequent pain in legs and arms. The general role of intervertebral discs is to provide the cushioning between vertebrae and absorb the pressure that is exerted on the spine. Generally low back pain(LBP) is considered as common disorder from disc degenerative diseases. The main reason of the LBP is due to contribution of intervertebral disc diseases and combination of genetic and environmental factors. Most of these factor identified, But some of these remain unidentified. However recent researches identified that variations in several genes may influence the risc of intervertebral disc diseases. Most of the variations associated with genes related with immune function leads to increase risk of intervertebral disc diseases. Most of these genes plays a vital role in immune response like inflammation and water loss (dehydration) of the discs, Which causes their degeneration. This review focuses on the evidence of genetic disposition, the genes or biological processes that are implicated, and the need to consolidate resources and clarify phenotype definition to take advantage of the new technologies in genetic analysis to enhance our understanding of this condition.
\end{abstract}

KEYWORDS: Genetic factor, Intervertebral disc degeneration, Degenerative disc disease, intervertebral disc degeneration, low back pain, nucleus pulposus, annulus fibrosus, endplate, extracellular matrix, Polymorphism

\section{INTRODUCTION}

Intervertebral disc (IVD) degeneration is a condition associated with both genetic and environmental factors. Research on IVD degeneration has focused largely on environmental factors but over the last two decades the genetic aspect has been recognized. Although the number of studies on genetic determinants of IVD degeneration has increased over time, little is known of the genetic processes that underlie thedevelopment of degeneration. The etiology of IVD degenerationremains unknown and the mechanisms attributed to it are poorly understood. The main cause of the LBP, The intervertebral disc degeneration(IDD) will be the most common diagnosis and target for intervention. In most cases IDD plays an important role LBP and also strongly it correlates with dysfunction and structural breakdown of the Intervertebral disc $(1,2)$. It has been estimated that almost $80 \%$ of all people have LBP during their lifetime with an annual point prevalence of about $30 \%$. It is a major factor affecting quality of life and individual suffering.IDD is the most important factor that limits the activity of the young peoples, Who are all below 45 years of age. The etiology of IDD is multifactorial related with aging, some diseases, injuries and some genetics factors also involved. Till now the mechanisms of IDD is not fully understood and a clear understanding of IDD will enable to create more targeted and invasive therapies to keep the peoples mobile and functional $(3,4)$. Here in this review it is going to focus on the recent advances in genetics mechanisms and polymorphisms associated with IDD.

\section{Genetic Risk factors for DDD}

Many studies have indicated contribution from familial aggregation and genetic influences, it was not clear whether there existed genes with a relatively strong effect. The intervertebral disc is composed of outer tough annulus fibrosus ,Type I collagen and with strong hydrophilic core called nucleus pulposus.There are many collages like type
II,IX and XI. The prime gene involved in type XI collagen formation is COLL11A1 had been found that it has low level expression in japans patients with lumbar disc degenerative diseases (5).Synthesis and break down of intervertebral discs is controlled by many type of different genes and it's biological process associated with the interaction of many environmental factors (6).Genetic changes concerned with nucleus pulposus plays a vital role in the developing lumbar disc herniation. Karasugi and his colleagues performed a study on 782 patients from hospitals in japan and finnish through MRI proved lumbar disc herniation the pain for more than 3 months. In many cases two type of single nucleotide polymorphisms (SNPs) of the SKT gene had high correlation with lumbar disc herniation, And also the malfunction in SKT result in abnormalities in nucleus pulposus which increase the risk of disc herniation(7). Intervertebral disc disease is a process of polygenic with involvement of many SNPs at different loci with variable and weak penetrance. Depending on the location of these SNPS along with these genes may silent or may lead over or under expression of different type of protein. A Volumetric bone mineral density (vBMD) study by zmuda and co workers investigated 4311 expressed sequence tags in 383 candidate genes found only 11 SNPs in 10 genes. In a another similar study by Grobler et al in 1991 and Matsui et al in 1992(8) were the first investigators at disc herniation at juvenile and adolescent patients suggested an underlying tendency phenotypically. These type of familial predisposition increased to 42 percent when compare the young children less than 17 years old was proved by a study from varlotta and 43.8 percent when the childrens younger than 18 years also were considered for this study by Frino et al . in 2006 (9). Such study finds that young give relative confidence that other risk factors such as age,smoking and occupation, have not yet had a major chance to confound the results.From those study it appears that high heritability of disc 
degeneration ranging from 34 percent to 61 percent. But the mode of inheritance in multigenic and multifactorial. However IVD heritability and its coding genes for the enzyme proteins, that break them down need to be investigated.

\section{Candidate genes of IVD}

\begin{tabular}{|c|c|c|c|}
\hline GENE & dbSNP1 & Location & Allele Change \\
\hline ADIP0Q & rs2241766 & Exon 2 & T/G \\
\hline CILP & rs2073711 & Exon 8 & $\mathrm{C} / \mathrm{T}$ \\
\hline COL9A2 & rs137853213 & Exon 19 & $\mathrm{C} / \mathrm{T}$ \\
\hline COL9A3 & rs61734651 & Exon 5 & $\mathrm{C} / \mathrm{T}$ \\
\hline COLL11A2 & rs1799907 & Intron & $\mathrm{T} / \mathrm{A}$ \\
\hline COLL22A1 & rs22929271 & Exon 3 & $\mathrm{C} / \mathrm{T}$ \\
\hline IL1A & rs1800587 & Promoter & $\mathrm{C} / \mathrm{T}$ \\
\hline IL1B & rs1143634 & Exon 5 & $\mathrm{C} / \mathrm{T}$ \\
\hline IL1F10 & rs3811058 & Exon 2 & $\mathrm{T} / \mathrm{C}$ \\
\hline IL6 & rs1800797 & Promoter & $\mathrm{G} / \mathrm{A}$ \\
\hline IL6 & rs1800796 & Promoter & $\mathrm{G} / \mathrm{C}$ \\
\hline IL6 & rs1800795 & Promoter & $\mathrm{G} / \mathrm{C}$ \\
\hline LEPR & rs1137100 & Exon 4 & $\mathrm{A} / \mathrm{G}$ \\
\hline LEPR & rs8179183 & Exon 12 & $\mathrm{G} / \mathrm{C}$ \\
\hline MMP9 & rs17576 & Exon 6 & $\mathrm{G} / \mathrm{A}$ \\
\hline MMP10 & rs470154 & Intron & $\mathrm{A} / \mathrm{C}$ \\
\hline SKT & rs16924573 & Intron & $\mathrm{G} / \mathrm{A}$ \\
\hline THBS2 & rs9406328 & Introns & $\mathrm{T} / \mathrm{C}$ \\
\hline VDR & rs10735810 & Exon 9 & T/C \\
\hline
\end{tabular}

\section{Polymorphism Associated With Disc Degeneration}

In DD there are more than 20 genes associated with polymorphisms have been analysed .Here it is grouped into five categories base on its protein encoded gene and its potential function in discs structural, catabolic, anti-catabolic and inflammatory level. Vitamin D receptor and growth differentiation factor 5(GDF5) make up other category. Other important molecules like Aggrecan, Collagen type I,IX and XI,fibronectin,hyaluronan and proteoglycan link protein1 (HAPLN1), thrombspondin, Cartilage Intermediate Layer Protein 1(CILP1) and aspirin grouped together because of it's contribution to the extra cellular matrix. Matrix Metalloproteinase (MMP) 1,2,3 and Parkinson Protein 2 E3 ubiquitin protein ligase (PARK2) and proteome subunit beta type 9 (PSMB9) are catabolic molecules and tissue inhibitor of metalloproteinases(TIMP) is an anti catabolic molecule. Many inflammatory cytokines such as Cyclooxygenese-2 (COX-2), IL-1 and IL-6.

Table: 1 Gene Categories

\begin{tabular}{|c|l|c|}
\hline \multirow{5}{*}{ Structural } & Aggrecan & ACAN \\
\cline { 2 - 3 } & Type I collagen & COL1 \\
\cline { 2 - 3 } & Type Ixcollagen & COL 9 \\
\cline { 2 - 3 } & Type XI collagen & COL 11 \\
\cline { 2 - 3 } & Fibronectin & FN \\
\cline { 2 - 3 } & Hyaluronan and Proteoglycan Link Protein 1 & HAPLN1 \\
\cline { 2 - 3 } & Thrombospondins & THBS \\
\cline { 2 - 3 } & Cartilage Intermediate Layer Protein & CILP \\
\hline \multirow{5}{*}{ Catabolic } & Matrix Metalloproteinase 1 & MMP1 \\
\cline { 2 - 3 } & Matrix Metalloproteinase 2 & MMP2 \\
\cline { 2 - 3 } & Parkinson Protein 2, E3 ubiquitin protein ligase & PARK2 \\
\cline { 2 - 3 } & Proteome subunit beta type 9 & PSMB9 \\
\hline \multirow{5}{*}{ Anti-Catabolic } & Tissue inhibitors of metalloproteinase & TIMP \\
\cline { 2 - 3 } & Interleukin 1 & IL1 \\
\cline { 2 - 3 } & Interleukin 6 & COX2 \\
\cline { 2 - 3 } & Cyclooxygenase 2 & GDR \\
\hline \multirow{2}{*}{ Other } & Vitamin D Receptor & \\
\cline { 2 - 3 } & Growth Differentiation Factor 5 & \\
\hline
\end{tabular}

Table 2 : Effect of the polymorphism on gene and protein level in the degeneration process

\begin{tabular}{|l|l|l|l|}
\hline Gene & \multicolumn{1}{|c|}{ Function } & \multicolumn{1}{|c|}{ Genetic Functional Change } & \multicolumn{1}{|c|}{$\begin{array}{c}\text { Protein Fuctional Change } \\
\text { (Contributing to Degeneration) }\end{array}$} \\
\hline VDR & $\begin{array}{l}\text { Modulate sulfate concentration } \\
\text { which is critical for sulfation of } \\
\text { proteoglycans }\end{array}$ & $\begin{array}{l}\text { FOK 1: Decreased transcription } \\
\text { factor binding results in decreased } \\
\text { functional VDR }\end{array}$ & $\begin{array}{l}\text { Decrease amount of sulfate } \\
\text { forproteoglycans results in } \\
\text { decreased functional proteoglycans }\end{array}$ \\
\hline GDF5 & Promotes growh and Repair & Decreased Transcription & Decrease Growth and Repair \\
\hline ACAN & Structure,Maintains Pressure & $\begin{array}{l}\text { Shorter Allele binds to less } \\
\text { chondrotin sulphate }\end{array}$ & Decrease functional proteoglycans \\
\hline
\end{tabular}


International Journal of Trend in Scientific Research and Development (IJTSRD) @ www.ijtsrd.com eISSN: 2456-6470

\begin{tabular}{|c|c|c|c|}
\hline COL 1 & Structure & $\begin{array}{l}\text { Increase transcription factor inding } \\
\text { results in increased collagen } \\
\text { a1(I)/a2 (I) product ratio }\end{array}$ & Impaired COL1 Protein \\
\hline COL 9 & Structure & $\begin{array}{l}\text { Addition of tryptophan- } \\
\text { Large,Hydrophobic,Less soluble } \\
\text { amino acid that is rare in collagen }\end{array}$ & $\begin{array}{l}\text { Decreased interaction with other } \\
\text { matric molecules }\end{array}$ \\
\hline COL 11 & Structure & Unstable Transcripts & Decreased Fuctional Collagen \\
\hline FN & Structure & Fragments & $\begin{array}{l}\text { Decreased Aggrecan, Increased } \\
\text { MMP }\end{array}$ \\
\hline $\begin{array}{l}\text { HAPLN } \\
1\end{array}$ & $\begin{array}{l}\text { Structure, Up-Regulate } \\
\text { aggrecan and type II collagen } \\
\text { synthesis }\end{array}$ & Altered Transcriptional Regulation & $\begin{array}{l}\text { Decreased amount of HAPLN1 } \\
\text { result in decreased aggrecan } \\
\text { stability }\end{array}$ \\
\hline THBS & Structure,Regulate MMP & Altered Transcriptional Regulation & Modulate amount MMP \\
\hline CILP & Structure,Inhibit TGF $\beta$ & $\begin{array}{l}\text { Increased binding to and inhibition } \\
\text { of TGF } \beta^{2}\end{array}$ & $\begin{array}{l}\text { Inhibit aggrecan and type II } \\
\text { collagen synthesis }\end{array}$ \\
\hline ASPN & Structure,Inhibit TGF $\beta$ & $\begin{array}{l}\text { Increased binding to and inhibition } \\
\text { of TGF } \beta\end{array}$ & $\begin{array}{l}\text { Inhibit aggrecan and type II } \\
\text { collagen synthesis }\end{array}$ \\
\hline MMP 1 & Catabolic & $\begin{array}{l}\text { Linkage disequilibrium with other } \\
\text { MMPs }\end{array}$ & Unknown \\
\hline MMP 2 & Catabolic & $\begin{array}{l}\text { Increased Transcription Factor } \\
\text { Binding }\end{array}$ & Increased MMP \\
\hline MMP 3 & Catabolic & Increased Promoter Activity & Increased MMP \\
\hline PARK 2 & Catabolic & Decreased Transcription & $\begin{array}{l}\text { Decreased Proteosomal } \\
\text { Degradation }\end{array}$ \\
\hline PSMB9 & Catabolic & Unknown & Unknown \\
\hline TIMP & Anti- Catabolic & Unknown Slenthf & Decreased TIMP \\
\hline IL-1 & Proinflammatory Cytokine & Increased Transcription & Increased IL1 and inflammation \\
\hline IL-6 & $\begin{array}{l}\text { Pro and anti-inflammatory } \\
\text { Cytokine }\end{array}$ & Unknown & Increased IL6 and inflammation \\
\hline $\operatorname{cox} 2$ & $\begin{array}{l}\text { Synthesis of prostanoids (Pain } \\
\text { Sensation) }\end{array}$ & Unknown ational Journal & $\begin{array}{l}\text { Increased COX 2,PGE2,Pain and } \\
\text { Inflammation. }\end{array}$ \\
\hline
\end{tabular}

\section{Collagens:}

Collagen is one of most abundant protein found in the human body. Almost more than 28 different types of collagen types found in human body. There are various types of collagens found in ECM to have different structural support roles Generally, collagen fibres are made up of three polypeptide chains referred ad $\alpha$ Chains that made one or more triple helix along with their rod shaped structure (10). In IVD patients there are many types of collagens of interests, Those are collagen I,II,IX and XI. The AF consists of fibril forming collagen otherwise known as collagen I. Fibrillar collagens I,II and III are essential in defining molecular and mechanical properties of particular tissue (10). Collagen I is responsible for maintaining tensile strength, withstand spinal compression and hydrostatic pressure in AF . Collagen II is otherwise known as primary collagen of the NP and generally it is found in loosely connected network (11) .Collagen IX forming crosslinks between different type of collagens and XI involved in structural support of collagen II as well as forming connections between proteoglycans and collagens(12). Taking everything into consideration the most important role of the collagen is to maintain the structural integrity of the IVD.

\section{Type IX Collagen}

Collagen is considered as a main structural components of intervertebral disc's nucleus pulposus andannulas fibrosus. Collagen IX has three alpha chains and it is encoded by the genes like COL9A1,COL9A2 and COL9A3.It has three collagenous(COL1 to COL 3) and four non Collagenous (NC1 to NC4) domains. Collagen IX plays an important role in constitution of intervertebral disc and the suitable candidate genes of Collagen IX is COL9A2 and COL9A3 better studied when compare with COL9A1. There are some common mutations in collagen genes like Trp ${ }^{2}$ allele of COL9A2 and $\operatorname{Trp}^{3}$ allele of COL9A3 leads to Gln326Trp substitution on the $\alpha 2$ chain and Arg103Trp substitution on the $\alpha 3$ chain. In a evident from finnish study on 157 patients found that mutation at the $\operatorname{Trp}^{2}$ allele present in 4percent of the symptomatic patients and none of the asymptomatic patients. In an another finnish study revealed that frequency of Trp ${ }^{3}$ allele was 12.2 percent among 171 individuals with radiologically proven lumbar disc degeneration(LDD)(13,14). Another large study from southern chinese population frequency of the $\operatorname{Trp}^{2}$ allele was found to be about 20 percent higher in contrast frequency of the $\operatorname{Trp}^{3}$ allele was completely absent when compare with finnish patients.

\section{COL9A2}

COL9A2 plays significant role in the pathogenesis of disc disease was prove from a study from annunen et al in 1999(15). Most of the studies in the COL2 revealed that the heterozygous substitution of Trp for either Gly ${ }^{326}$ and Arg ${ }^{326}$. Because of Trp rarely found in collagenous domain and also no Trp residues in the collagenous domains of Collagen IX in humans or in the mouse(16).Trp may interfere with the interaction between collagens IX and II and also disrupt the triple helix. Annunen et al analyzed all the exons and exon boundaries of COL9A2 by sensitive gel electrophoresis to reveal the Trp substitution, But this study didn't identify any coding sequence or RNA splice sites , besides it indicated two additional changes, An A to $G$ change affecting the third nucleotide in the codon for proline (CCA to CCG) at nucleotide 9 in exon 21 and $\mathrm{G}$ to A change at nucleotide +17 
in intron 30. From these type of similar studies Trp allele substitution was found to be 4 percent and 20 percent in different regions $(17,18)$.

\section{COL9A3}

In a study from the finnish population by petteri et al (19) revealed that $\operatorname{Trp}^{3}$ substitution in COL9A3 had high risk of disc disease nearly 3 fold compared with an individual without $\operatorname{Trp}^{3}$. The site mutation on $\operatorname{Arg} 103$ to $\operatorname{Trp}$ substitutions in the a3(IX) chain. In an another study on LDD from 164 individulas including321 controls and 186 healthy,83 with osteoarthritis, 31 with rheumatoid arthritis and 21 with chondrodysplasia showed the frequency of the $\operatorname{Trp}^{3}$ allele as 12.2 percent in the case sample and 4.7 percent in control group. Data received from these study revealed that $\operatorname{Trp}^{3}$ allele may cause lumbar disc disease. But the Trp ${ }^{3}$ allele association in finnish population has not been successfully replicated in the greek population.A study by solovieva's by MRI was found to be carriage of the Trp ${ }^{3}$ allele in the abscence of IL-1 beta T (3954) allele increased the risk of dark nucleus pulposus and joint occurrence of degenerative changes. This result indicated that the effect of COL9A3 gene polymorphism on disc degeneration modified by the gene polymorphism of IL-1 beta . The Trp ${ }^{3}$ allele changes associated with scheuermann disease(20).

\section{Type I Collagen}

Collagen I is otherwise known as important incredients in annulus fibrosus. The risk of disc degeneration was higher in the peoples with genotype TT when compare with genotype GG or GT genotype was proved by pluijm and Tilkeridis (21). Another researcher Mann found that presence of the T allele in the COLIA1 Sp1 binding site has many functional effects on the collagen gene regulation and also it leads to higher COLIA1 mRNA, protein expression level and COLIA1 /COLIA2 protein ratio. Abnormal ratio of collage in human associated with impaired bone structure. The Sp1 binding site of COLIA1 and it's intronic polymorphism may affect the transcription of Collagen I. It is indispensable to find the relationship between the binding site Sp1 on COLAIA1 and disc degeneration by the analysis of large sample size. However it is still unclear that, how the disc degeneration is formed due to the in collagen I and also it needs further investigation.

\section{SOX 9}

SOX9 is one of a gene from the family of mammalian Y linked testis determining gene Sry (22).Many transcription encoded by SOX genes with diverse role differentiation and development. Generally prior to mesenchymal condensations or during chondrogenesis SOX9 is expressed and it is activating the Col2a1, and this encoding the some major component of cartilage matrix $(23,24)$ and type II collagen. One of the primary role of the SOX9 is to regulate the genes that is coding for Aggrecan(25) and type XI collagen. SOX 9 is also regulates the cartilage and bone development other structural and patterning gene(26).Nucleus pulposus cells also having the expression and regulation of SOX 9 gene. A study by Paul et al explored the SOX 9 for the gene therapy of disc degenerative diseases(45).The used the gene delivering system of adenoviral delivery vectors that expressing SOX 9 to increase the production of TYPE II collagen, by infecting chondroblastic cell line and human disc cells . Gruber et al explained the loss of expression in SOX 9 in some of the annulus cell population may play a role disc aging and regeneration. Also SOX9 decrease the modulation of expression and production of Type II collagen disc cells(27).

\section{Collagen XI}

Collagen XI is a heterotrimer is having similar structure to collagen collage IX. The three $\alpha$ chains like $\alpha 1, \alpha 2$ and $\alpha 3$ coded by collagen type XI $\alpha 1$ (COLL11A1), collagen type XI $\alpha 2$ (COL11A2)and collagen type II $\alpha 1$ (COL2A1) respectively(28). Collagen XI found in both AF and NP of IVDs and also it plays important role in the connection of different collagen molecule, Particularly collagen II as well as it connects proteoglycan with some other collagens(29). Solovieva et al showed a relationship between G to A substitution SNP within introns 9 of COLL11A2 and disc bulging(49).Patients with the SNP alleles carriers had increased risk of disc bulging when the patients didn't carry the SNP allele. Also G to A SNP of COLL11A2 was related to change associated with disc degeneration. Five different polymorphisms in collgen XI gene was documented from a study by Videman et al in 2009, and also it was significantly associated with sign of disc degeneration and reduced disc signal and bulging(30).One of the major study from 588 enrolled finnish male twins ranging from 35 to 70 years of age. SNPs like rs2072915, rs9277933 and rs2076311 of COLL11A1 were significantly associated with reduced disc signal, Whereas the rs1337185 and rs1463035 polymorphisms of COLL11A1 were significantly associated with increase risk of disc bulging.

\section{Vitamin D Receptor}

Vitamin D Receptor plays a important role in the normal bone mineralization and remodelling and it's gene polymorphisms correlate with some diseases(31). The vitamin D receptor gene and it's tt of TT allele were associated with multilevel and severe disc degeneration, Disc herniation. Also TT allele increased the risk of disc disease at an early age pointed out in the Vitamin D Receptor gene. According to a study from jones et al (32) association of allelic variations in the Vitamin D Receptor gene and spinal degenerative disease found a decrease in the risk of spinal osteophytosis, tt and TT associated disc narrowing . Spinal osteophytosis and disc narrowing are closely related to disc degeneration. Two intergenic polymorphism of the vitamin D Receptor gene was found by videman et al associated with disc degeneration and also assessed the signal intensities of thoracic and lumbar quantitatively and the the discs were $12.9 \%$ worse in ment with the Taq1 tt genotype and 4.5 percent worse in men with the Tt genotype , Compared with signal intensity in men with the TT genotype. Another similar pattern like men with ff and FF genotype was found between disc signal intesnsity and Fok 1 Polymorphisms.Cheung et al (33) proved that the high risk of disc degenerative diseases and it's consecutive disc bulging in peoples younger than 40 years associated with the $t$ allele of vitamin D receptor Taq I . Direct involvement of vitamin $\mathrm{D}$ receptor in differentiation, Proliferation and maturation of cartilage cells was found by Balmain et al (34).In addition to that proteoglycan synthesis also influenced by vitamin D through articular chondrocytes in vitro(35) . Due to rich proteoglycan of intervertebral disc disease vitamin $D$ receptor directly involved in the pathophysiology of the degenerated intervertebral disc. Furthermore Kawaguchi et al considered the possibility of vitamin D receptor gene polymorphism in pathogenesis, Buy they found that it is not directly involved in the pathogenesis 
of lumbar disc disease, Instead of that it acts as a marker for other genes.

\section{Fibronectin}

Fibronectin is an extracellular glycoprotein that helps organization of the extracellular matrix(36).Fibronectin accelerate the matrix-matrix interactions through binding with other collagens and function in cell adhesion, migration, differentiation, and regulates cell matrix. More than 20 different type of fibronectin variants fragments produced due to the alternative splicing at three major sites like EDA,EDB and V. Evidence is growing to suggest that these isoforms affect fibronectin function. Due to the similarity of cellular and extra cellular matrix properties between cartilage and intervertebral discs, Fibronectin fragments may play a role in disc degeneration(37). A study by Oegema et al(38) found an association between FN fragments and MRI defined degeneration, but didn't specify the size of the fragment. Fibronectin may contribute to the degeneration of the disc through the stimulation of MMP production as in done in chondrocytes. A recent study at FN splice variants found higher levels of EDB+ in degenerated discs compared to controls, Suggesting it's potential contribution to degeneration. However these studies failed to explain the genetic relationship with degeneration because of many non genetic components could affect or regulate the gene splicing.

\section{Matrix Metalloprotease-3}

Matrix metalloproteases - 3 (MMP-3) plays an important role in the degeneration and it's associated intervertebral discs. MMP-3 expression is induced in response to local condition such as mechanical loading and inflammation(39). A common polymorphism in the promoter region of the human MMP-3 gene is 5A/6A has been identified(40).This type of polymorphism was reported to be involved in the regulation of MMP-3 gene expression with the $5 \mathrm{~A}$ allele having twice as much promoter activity as the $6 \mathrm{~A}$ allele(41).A study from elderly Japanese subjects Takahashi et al (42) found that the 5A5A AND 5A6A genotype in the elderly was associated with a significantly larger number of degenerative intervertebral discs than the 6A6A, But there was no significant difference in the young. Indication of $5 \mathrm{~A}$ allele of the human MMP-3 promoter from these studies may be important risk factor for the acceleration of intervertebral disc degeneration in the older population.

\section{Chondroitin Sulphate}

The nucleus pulposus and it's ECM contains large aggregating proteoglycans called called Aggrecan. Proteoglycans have a core protein in which attaches glycosaminoglycans (GAGs), namely chondroitin sulphate and keratin sulphate and it forms a large protein polysaccharide molecules through binding with hyaluronic acid via link protein to form the aggregates. Initially the collagens and aggrecans forms a composite organic matrix through interaction and that is strongly hydrophilic that resist compressive force. This function is based on the number of chondroitin sulphate is attached to the core protein. Chondrotin sulphates attached to the two adjacent areas of the aggrecans called CS1 and CS2 and the gene coding for CS1 exhibits size polymorphisms(43) . A study from young japanese womens by kawaguchi and co-workers (44) revealed that multilevel disc degeneration was associated with shorter expressed VNTR polymorphism for the chondrotin sulphate attachment on the core protein .
Another study by soloviva et al from 132 middle aged finnish mens showed VNTR polymorphism significantly associated with higher risk of disc degeneration.The risk of dark nucleus pulposus was increased with the individuals who were homozygous for the A26 allele.

\section{Cytokines:}

Cyokines ,such as IL-6,IL-1a,IL-1b and tumor necrosis factor(TNF- $\alpha$ ) are some of the key pro inflammatory mediators that are found and released at sites of tissue injury. IL-1 is naturally found within the IVD and is responsible for indirectly degrading ECM components through the production of degradative enzymes and upregulation of other cytokines and preventing the production of ECM components (45).IL-1 has three different subtypes IL-1a,IL-1b and IL-1RN. The alpha and beta subtypes are pro inflammatory and IL-1RN anti inflammatory. SNP associated with Interleukin 1 alpha (IL1A) involved in IVDD revealed from a study on 150 finnish men by Virtanen et al.Here the SNP is an -889 C/T substitution, Where the $\mathrm{T}$ allele is the risk allele. In this study patients with TT genotype were at a 7.87 fold increased risk of developing IVDD when compare the patients with CC genotype. These findings were also supported by Eskola et al in 2012 from dannish adolescents(78). Also this study found that 2.82 fold increased risk of IVDD among girls who were the carriers of the T allele compared with the control. These two studies along with some other studies established that $889 \mathrm{C} / \mathrm{T}$ SNP of IL1A as a genetic risk factor for IVDD. Another cytokines like IL- 6 is an important factor that mediates inflammation and also involved with lumbar disc herniation(46).But the exact role of IL-6 still remain unknown.Noponen-Hietla et al documented an SNP in the IL6 that was significantly associated with IVDD(79).Another study reported that $15 \mathrm{~T} / \mathrm{A}$ substitution was located within exon 5 of IL6. Statistical analysis showed that the patients with the AA or AT genotypes were at 4.4 fold increased risk of IVDD than patients with TT genotype. Inflammatory cytokines have a well recognized contribution to the generation of back pain . Generally disc degeneration by IL-1 through inducing the related enzymes that destroy proteoglycans and mediates pain. The IL-1 genes and it's TT genotype was associated with more than 3 fold increase in the risk of disc bulges among middle aged occupationally active men. The polymorphisms were associated with 2.5 fold increased risk of back pain. Besides these studies researchers tested polymorphisms of genes that trigger and express inflammatory factors and found some of the same polymorphisms explained by valdes such as CD36,COX2, NCOR2,TNA and ESR1 affecting knee OA susceptibility. Also polymorphisms in cartilage gene and it's intermediate layer protein were associated with the pathogenesis of lumbar disc disease.

\section{Coclusion:}

It is estimated that about 1000 cases and 1000 controls are required for each study to have sufficient power to identify susceptibility genes with only a moderate effect. Despite the continuous research the etiology and pathophysiology underlying IVDD remain poorly understood. Understanding of IVDD has started past two decades and now roughly we came to know the 75 percent of etiology is behind IVDD is genetic. Large scale DNA arrays and Sequencing technologies evolved as a important techniques to analyse large human samples and polymorphisms with the help of novel computational methodologies bring to light many SNPs and 
related mutations associated with Disc Degenerative Diseases, That were not previously reported with IVDD. Also with increasing advanced technology understanding pathophysiology of IVDD will produce more innovative and new therapeutic approaches. Analysis of whole genomes through the rapid analysis of next generation sequencing system is leading to the possibility personalised medicine can become a reality. These comprehensive analysis of literature review not only providing the knowledge about understanding the molecular mechanisms behind IVDD, Also it will help for the physician to find more effective targeted therapies for the patients . Consequently DNA screening for the genetic variants explaining the pathophysiology of the patients IVDD should be the standard of care.

\section{REFERENCES}

[1] Galbusera F, van Rijsbergen M, Ito K, Huyghe JM, Brayda-Bruno M, Wilke HJ. Ageing and degenerative changes of the intervertebral disc and their impact on spinal flexibility. European spine journal: official publication of the European Spine Society, the European Spinal Deformity Society, and the European Section of the Cervical Spine Research Society. 2014;23(Suppl 3):S324-332.

[2] Richardson SM, Kalamegam G, Pushparaj PN, et al. Mesenchymal Stem Cells in Regenerative Medicine: Focus on Articular Cartilage and Intervertebral Disc Regeneration. Methods (San Diego, Calif) 2015

[3] Wang SZ, Rui YF, Lu J, Wang C. Cell and molecular biology of intervertebral disc degeneration: current understanding and implications for potential therapeutic strategies. Cell proliferation. 2014; 47(5):381-390.

[4] Weber KT, Jacobsen TD, Maidhof R, et al. Developments in intervertebral disc disease research: pathophysiology, mechanobiology, and therapeutics. Current reviews in musculoskeletal medicine. 2015;8(1):18-31.

[5] Min et al. The cartilage intermediate layer protein gene is associated with lumbar disc degeneration in collegiate judokas. International Journal of Sports Medicine 2009 30(9), 691-694

[6] Kizawa et al. An aspartic acid repeat polymorphism in asporin inhibits chondrogenesis and increases susceptibility to osteoarthritis. Nature Genetics 2005 $37(2), 138-144$

[7] Karasugi et al. Association of the Tag SNPs in the Human SKT gene (KIAA1217) with lumbar disc herniation. Journal of Bone and Mineral Research 2009 vol 24 (9), 1537-1543

[8] Mustafa et al. Investigating the aspartic acid (D) repeat of asporin as a risk factor for osteoarthritis in a UK Caucasian population. Arthritis and Rheumatism 2005 52(11), 3502-3506

[9] Gruber et al. Asporin, a susceptibility gene in osteoarthritis, is expressed at higher levels in the more degenerate human intervertberal disc. Arthritis Research and Therapy 2009 11(2), R47

[10] Ricard-Blum S. The collagen family. Cold Spring Harb Perspect Biol (2011) 3(1):a004978. doi:10.1101/cshperspect.a004978
[11] Kadow T, Sowa G, Vo N, Kang JD. Molecular basis of intervertebral disc degeneration and herniations: what are the important translational questions? Clin Orthop Relat Res (2015) 473(6):1903-12. doi:10.1007/s11999-014-3774-8

[12] Kepler CK, Ponnappan RK, Tannoury CA, Risbud MV, Anderson DG. The molecular basis of intervertebral disc degeneration. Spine J (2013) 13(3):318-30. doi:10.1016/j.spinee.2012.12.003

[13] Kimura T, Nakata K, Tsumaki N, et al. Progressive degeneration of articular cartilage and intervertebral discs. An experimental study in transgenic mice bearing a type IX collagen mutation. International orthopaedics. 1996; 20(3):177-181. [PubMed: 8832322]

[14] Boyd LM, Richardson WJ, Allen KD, et al. Early-onset degeneration of the intervertebral disc and vertebral end plate in mice deficient in type IX collagen. Arthritis and rheumatism. 2008; 58(1):164-171. [PubMed: 18163498]

[15] Annunen S, Paassilta P, Lohiniva J, Perälä M, Pihlajamaa T, Karppinen J, Tervonen O, Kröger H, Lähde S, Vanharanta H, Ryhänen L, Göring HH, Ott J, Prockop DJ, Ala-Kokko L.An allele of COL9A2 associated with intervertebral disc disease. Science. 1999;285:409-412

[16] Muragaki Y, Kimura T, Ninomiya Y, Olsen BR. The complete primary structure of two distinct forms of human alpha 1 (IX) collagen chains. Eur J Biochem. 1990;192:703-708

[17] Jim JJ, Noponen-Hietala N, Cheung KM, Ott J, Karppinen J, Sahraravand A, Luk KD, Yip SP, Sham PC, Song YQ, Leong JC, Cheah KS, Ala-Kokko L, Chan D. The TRP2 allele of COL9A2 is an age-dependent risk factor for the development and severity disc degeneration. Spine. 2005;30:2735-2742

[18] Tigashino K, Matsui Y, Yagi S, Takata Y, Goto T, Sakai T, Katoh S, Yasui N. The alpha2 type IX collagen tryptophan polymorphism is associated with the severity of disc degeneration in younger patients with herniated nucleus pulposus of the lumbar spine. Int Orthop. 2007;31:107-111

[19] Paassilta P, Lohiniva J, Göring HH, Perälä M, Räinä SS, Karppinen J, Hakala M, Palm T, Kröger H, Kaitila I, Vanharanta H, Ott J, Ala-Kokko L. Identification of a novel common genetic risk factor for lumbar disc disease. JAMA. 2001;285:1843-1849

[20] Karppinen J, Pääkkö E, Paassilta P, Lohiniva J, Kurunlahti M, Tervonen O, Nieminen P, Göring HH, Malmivaara A, Vanharanta H, Ala-Kokko L. Radiologic phenotypes in lumbar MR imaging for a gene defect in the COL9A3 gene of type IX collagen. Radiology. 2003;227:143-148

[21] Tilkeridis C, Bei T, Garantziotis S, Stratakis C. Association of a COL1A1 polymorphism with lumbar disc disease in young military recruits. J Med Genet. 2005;42:e44

[22] Wright E, Hargrave MR, Christiansen J, Cooper L, Kun J, Evans T, Gangadharan U, Greenfield A, Koopman P. The Sry-related gene Sox 9 is expressed during 
International Journal of Trend in Scientific Research and Development (IJTSRD) @ www.ijtsrd.com eISSN: 2456-6470

chondrogenesis in mouse embryos. Nat Genet. 1995;9:15-20

[23] Bell DM, Leung KK, Wheatley SC, Ng LJ, Zhou S, Ling KW, Sham MH, Koopman P, Tam PP, Cheah KS. SOX9 directly regulates the type-II collagen gene. Nat Genet. 1997;16:174-178

[24] Lefebvre V, Huang W, Harley VR, Goodfellow PN, Crombrugghe B. SOX9 is a potent activator of the chondrocyte-specific enhancer of the pro alpha1(II) collagen gene. Mol Cell Biol.1997;17:2336-2346

[25] Sekiya I, Tsuji K, Koopman P, Watanabe H, Yamada Y, Shinomiya K, Nifuji A, Noda M. Sox9 enhances aggrecan gene expression via the promoter region containing a signal HMG-BOX-sequence in a chondrogenic cell line, TC6. J Biol Chem. 2000;275:10738-10744

[26] Genzer MA, Bridgewater LC.A Col9a1 enhancer element activated by two interdependent SOX9 dimers. Nucleic Acids Res. 2007;35(4):1178-86

[27] Gruber HE, Norton HJ, Ingram JA, Hanley EN Jr. The SOX9 transcription factor in the human disc: decreased immunolocalization with age and disc degeneration. Spine. 2005;30:625-630

[28] Kepler CK, Ponnappan RK, Tannoury CA, Risbud MV, Anderson DG. The molecular basis of intervertebral disc degeneration. Spine J (2013) 13(3):318-30. doi:10.1016/j.spinee.2012.12.003

[29] Mayer JE, Iatridis JC, Chan D, Qureshi SA, Gottesman O, Hecht AC. Genetic polymorphisms associated with intervertebral disc degeneration. Spine J (2013) 13(3):299-317. doi:10.1016/j.spinee.2013.01.041

[30] Videman T, Saarela J, Kaprio J, Nakki A, Levalahti E, Gill $\mathrm{K}$, et al. Associations of 25 structural, degradative, and inflammatory candidate genes with lumbar disc desiccation, bulging, and height narrowing. Arthritis Rheum (2009) 60(2):470-81. doi:10.1002/art.24268

[31] Videman T, Gibbons LE, Battie MC, Maravilla K, Vanninen E, Leppavuori J, Kaprio J, Peltonen L. The relative roles of intragenic polymorphisms of the vitamin D receptor gene in lumbar spine degeneration and bone density. Spine. 2001;26:E7-E12

[32] Kawaguchi Y, Kanamori M, Ishihara H, Ohmori K, Matsui H, Kimura T. The Association of Lumbar Disc Disease with Vitamin-D Receptor Gene Polymorphism. J Bone Joint Surg Am.2002;84A:20222028

[33] Cheung KM, Chan D, Karppinen J, Chen Y, Jim JJ, Yip SP, Ott J, Wong KK, Sham P, Luk KD, Cheah KS, Leong JC, Song YQ. Association of the Taq I allele in vitamin D receptor with degenerative disc disease and disc bulge in a Chinese population. Spine. 2006;31:1143-1148

[34] Balmain N, Hauchecorne M, Pike JW, Cuisinier-Gleizes $\mathrm{P}$, Mathieu H. Distribution and subcellular immunolocalization of 1, 25-dihydroxyvitamin D3 receptors in rat epiphyseal cartilage. Cell Mol Biol (Noisy-le-grand). 1993;39:339-350
[35] Corvol MT, Dumontier MF, Tsagris L, Lang F, Bourguignon J.Cartilage and vitamin $\mathrm{D}$ in vitro (author's transl). Ann Endocrinol (Paris). 1981;42:482487

[36] Xu S, Liang T, Li S. Correlation between polymorphism of TRAIL gene and condition of intervertebral disc degeneration. Med Sci Monit (2015) 21:2282-7. doi:10.12659/MSM.894157

[37] Homandberg GA, Costa V, Wen C. Fibronectin fragments active in chondrocytic chondrolysis can be chemically cross-linked to the alpha5 integrin receptor subunit. Osteoarthritis Cartilage. 2002; 10(12):938-49.

[38] Oegema TR Jr, Johnson SL, Aguiar DJ, Ogilvie JW. Fibronectin and its fragments increase with degeneration in the human intervertebral disc. Spine (Phila Pa 1976). 2000; 25(21):2742-7.

[39] Ito A, Mukaiyama A, Itoh Y, Nagase H, Thogersen IB, Enghild JJ, Sasaguri Y, Mori Y. Degradation of interleukin 1betaby matrix metalloproteinases. J Biol Chem. 1996;271:14657-14660

[40] Ye S, Watts GF, Mandalia S, Humphries SE, Henney AM. Preliminary report: genetic variation in the human stromelysin promoter is associated with progression of coronary atherosclerosis. Br Heart J. 1995;73:209-215

[41] Ye S, Eriksson P, Hamsten A, Kurkinen M, Humphries SE, Henney AM. Progression of coronary atherosclerosis is associated with a common genetic variant of the human stromelysin-1 promoter which results in reduced gene expression.J Biol Chem. 1996;271:13055-13060

[42] Takahashi M, Haro H, Wakabayashi Y, Kawa-uchi T, Komori H, Shinomiya K. The association of degeneration of the intervertebral disc with $5 \mathrm{~A} / 6 \mathrm{~A}$ polymorphism in the promoter of the human matrix metalloproteinase-3 gene. J Bone Joint Surg. 2001;83B:491-495

[43] Roughley P, Martens D, Rantakokko J, Alini M, Mwale F, Antoniou J. The involvement of aggrecan polymorphism in degeneration of human intervertebral disc and articular cartilage. European cells \& materials. 2006; 11:1-7. discussion 7. [PubMed: 16425147]

[44] Kawaguchi Y, Osada R, Kanamori M, et al. Association between an aggrecan gene polymorphism and lumbar disc degeneration. Spine. 1999; 24(23):2456-2460.

[45] Kepler CK, Ponnappan RK, Tannoury CA, Risbud MV, Anderson DG. The molecular basis of intervertebral disc degeneration. Spine J (2013) 13(3):318-30. doi:10.1016/j.spinee.2012.12.003

[46] Eskola PJ, Kjaer P, Sorensen JS, Okuloff A, Wedderkopp $\mathrm{N}$, Daavittila I, et al. Gender difference in genetic association between IL1A variant and early lumbar disc degeneration: a three-year follow-up. Int J Mol Epidemiol Genet (2012) 3(3):195-204. 